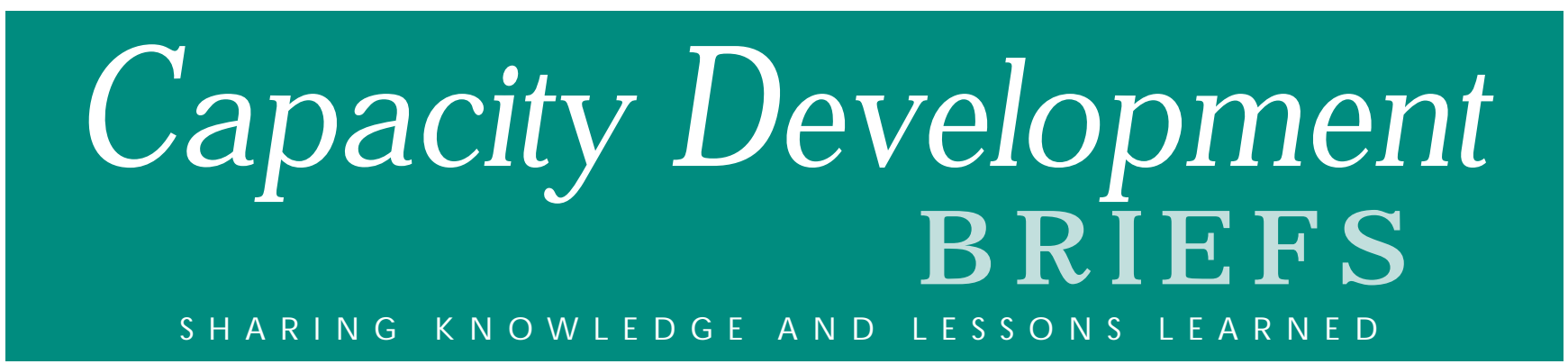

\title{
THE FM REVOLUTION IN NIGER: RADIO'S IMPACT ON CAPACITY DEVELOPMENT
}

\section{By Luc Peter, Stephanie Barbey, and Ajay Tejasvi}

In Niger, where only a fifth of the population is literate and poverty is rife, radio has taken on an extraordinarily important role in the lives of its citizens. Radio programs are not only the means through which people entertain themselves and get the daily news, they are also playing a proxy role for the health clinics, schools, social support networks, and continuing education needed for economic progress. Women debate their role in society; citizens call in to complain about poor local services; radio reporters, microphones in hand, chase down politicians and demand answers on the air. Although Niger has a long way to go in creating a viable and free media market, radio has nevertheless flourished in a remarkable way in this landlocked francophone country of 13 million and given people a taste of democracy. Providing the citizens of Niger with perspectives from around the world, radio is a major instrument in the process of capacity development in the country.

Exploring life's bigger lessons to its smaller ones, the radio is always on in Niger, constantly educating, entertaining, and helping people keep a check on power. In a nation with more than 80 percent illiteracy, the radio has become the main means of communication. Simple yet reliable, radios are everywhere: in homes, on streets and in the bush. Today, through the radio waves, the citizens of Niger are seizing the microphone and tasting democracy. In Niger, they call it "Révolution FM," because radio is contributing to the strengthening of the young democracy and increasing public awareness about the Niger's economic and social progress.

\section{Going beyond Barriers}

The radio revolution in Niger is usually said to have begun in 1990 with the advent of democracy. Since then, many private radio stations have sprung up to defy the previous monopoly of the state media. This more diverse and competitive radio market has already left its mark, turning radio into the main channel through which a range of forces in society can address citizens and citizens can confer with each other, as well as helping the people of Niger to understand the concepts of free thinking and democracy. It has also brought ideas and news from the rest of the world to Niger's doorstep. A multitude of topics-politics and governance, marital and social councils, health and beauty tips, cooking recipes, public awareness campaigns, music and entertainment-are now available to ordinary people through radio.

Because of low literacy and personal incomes, radio has become an important instrument of capacity development in Niger. Radio stations broadcast programs on preventive health and current affairs and with lessons for school children and advice for farmers; as a result, most people who had no prior access to any such information are now able to make more informed decisions. Farmers from the Sahel region and those without any access to primary health care have benefited from these programs. La Voix du Sahel provides news and other programs in French and several local languages. Radio also brings news from as far as the United States, France, and Hong Kong. As a result of all the new information available to them, people have

This brief is primarily based on the 2007 documentary film "Magic Radio" by Luc Peter and Stephanie Barbey, produced by Intermezzo Films (intermezzo@freesurf.ch). The direct quotes and interviews cited in this brief come from the film. It was written by A jay Tejasvi at the World Bank Institute. 
"Respect your neighbor and treat him as you would treat yourself. That's the most important thing in life. The radio educates me. It puts things in my head that I could never have imagined."

$$
\text { -A listener in Niger }
$$

started demanding more action and responsiveness from the government and public agencies.

\section{Free Speech in the Balance}

Technology has played a role in this Révolution FM, leading to a reduction in setup and broadcast costs. An operational radio station can be set up with a budget of around $\$ 15,000$ and can service a radius of 50 miles. This is a fivefold reduction in expenses compared with the 1980s. A low-level transmitter of several watts, capable of reaching a village, can now be set up for less than $\$ 800 .{ }^{1}$ Lower transmission costs and a greater range of broadcasts, combined with the low cost of FM transistor radios (around \$5 each), have brought the radio with in the reach of the poor.

Despite all this progress, free speech remains fragile in Niger. The government recently declared a state of emergency in the north and has restricted journalists' broadcasts on and photography of the rebellion. The government closed a private newspaper, Air Info in the northeast, imposed a three-month ban on a radio talk show on Radio France International (RFI), and brought corruption charges against journalists who alleged corruption in the government's management of a donor-funded public education initiative. ${ }^{2}$ Such actions are a step back in a fledgling democracy. Niger's President Mamadou Tandja promised during his 2004 campaign to abolish prison penalties for press-related offenses. A government commission

\section{Table 1: Niger at a Glance}

Life expectancy at birth

Adult literacy rate (ages 15 and older)

Combined gross enrollment in primary, secondary, and tertiary education

Total population

GDP per capita

Public health expenditure per capita (purchasing power parity)

Public education expenditure (percent of GDP)

Main telephone lines (per 1,000)

Cellular subscribers (per 1,000)

Source: UNDP (2006).
Box 1: Messages in Music: Niger's hip-hop

"I have to go, despite the peace,

Despite the hospitality.

I have to go.

Too tough being young here

To live, deadly burden,

Doubts in our heads.

Sad to know tomorrow will be worse.

Tough not knowing how to end it.

I have to go

To Paris or Uncle Sam

Aware of all the dangers

I know that over there...

I have to go to new horizons

So that one day when I return

My words will make sense...

-Zara Moussa (ZM), Niger's hip-hop sensation.

proposed last year replacing prison sentences with fines, but the 1999 press law remains unchanged.

The media in Niger, as in many other African countries, is also struggling to create a viable market in which news and information flow freely and various types of media contribute to the national debate. The media face a variety of obstacles, including poor management, lack of independent funding resources, undeveloped advertising markets, and other political and economic pressures. It is unclear just how many radio stations are operating at any one time in the country, although international organizations active in the sector put the number at more than 100 .

\section{Listening and Learning}

In Niger, both state-owned and private radio stations have contributed to Révolution FM. One of the strengths of private and community radio is that it covers news and discussion that might be censored or avoided on

“For a country like Niger, radio is truly magical. A newspaper is no good to people who are illiterate. But if you report the news in his own language, the same way he talks, then he understands. He keeps it in his head; you make him aware of things. He understands more because it is closer to him than a newspaper. It is a great tool for educating the masses."

\section{-A listener on government-owned La Voix du} Sahel (Voice of Sahel)

\footnotetext{
${ }^{1}$ See Sposato and Smith (2005).

2 See entry for Niger in WAN (2007), p. 315.
} 
In the Neighborhood: Voice and Accountability (2006)

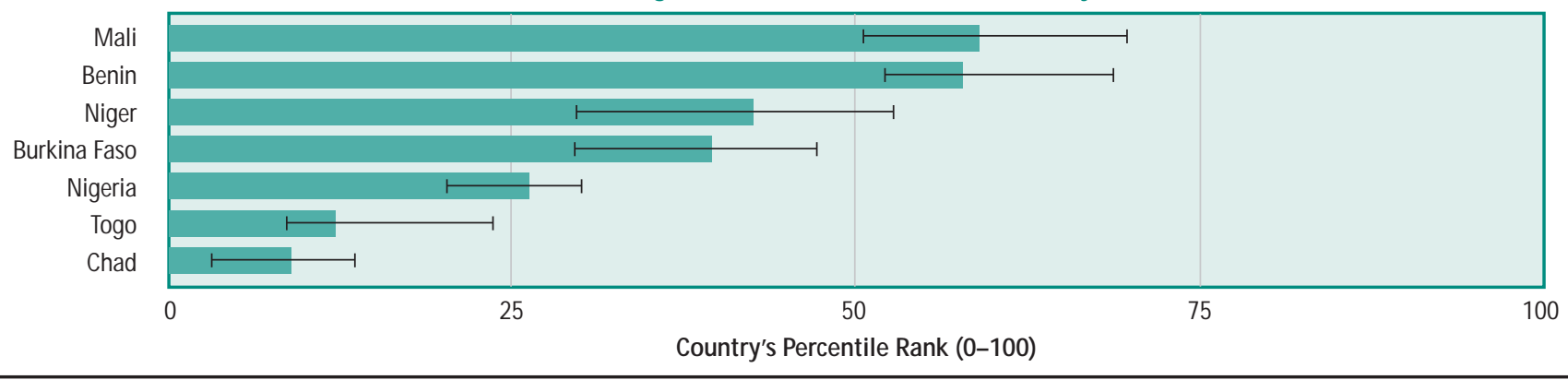

Source: Kaufmann, Kraay, and Mastruzzi (2007).

Note: The governance indicators presented here aggregate the views on the quality of governance provided by a large number of enterprise, citizen, and expert survey respondents in industrial and developing countries. These data are gathered from a number of survey institutes, think tanks, and nongovernmental and international organizations. The aggregate indicators do not reflect the official views of the World Bank, its Executive Directors, or the countries they represent. Countries' relative positions on these indicators are subject to indicated margins of error that should be taken into consideration when making comparisons across countries and with time.

state- owned radio: a meeting of the opposition, political debates, and social issues otherwise not covered by the national media. Local stations also tackle issues of importance to local communities that are ignored in the national media. Today's Niger has 21 living languages; local radio stations move back and forth among the many local languages that are typically spoken.

Youth see radio as a means of speaking out for social change. Zara Moussa or ZM, Niger's hip-hop sensation, addresses social evils in her music. She campaigns for women's rights and works to bring hope to women who have always been marginalized in Niger's society. She inspires young people to shed old mindsets and embrace new ideas for development. Her music also speaks about the problems and confusion facing youth in Niger today.

"The way to health is open. The way to medicine is open: the important way. Dear listeners to Voice of Sahel, Hello! We're going to talk about a disease that is caught from water. It concerns ponds and stagnant water. This disease is not contracted by drinking the water, but by bathing in it or washing clothes in it. This is when the parasites enter the body through the pores of the skin on the feet. This disease has been known about for a very long time. It is called bilharzia."

$$
\begin{array}{r}
\text { - Health worker Damoure Zika on } \\
\text { La Voix du Sahel }
\end{array}
$$

Damoure Zika's informative show has been on the air since 1958, making people aware of hygiene and health. As the show's anchor, Zika notes that in the early years of independence from France, there weren't many doctors or nurses, nor were there any free health centers. So every Friday, people would listen to the radio to learn about diseases. Even today, Niger spends
Box 2: Excerpt from a Special Radio Show on Radio Anfani for Children

\section{Host: "How many days does a year have?" Child 1: "365 days"}

\section{Host: "Excellent! Now who can give me a good life lesson?}

Child 2: "Cleanliness ... I must wash myself with soap and water to be clean."

less than 3 percent of its gross domestic product on health care. ${ }^{3}$ It is in this context that Niger's radio helps build public health capacity and gives people a chance for a better life. More people now get health tips from the radio than through any other medium.

Every week in Niger, women radio hosts talk about the problems facing women and inspire common folk to participate in reforming their society. Be it child marriage or dowry harassment, a new cake recipe or beauty tips, women are rising to the challenge and redrawing the lines of engagement.

In a country that ranks at the bottom of the human development index ${ }^{4}$ radio is also playing a role in primary education and is being used to transmit school lessons. The United States A gency for International Development (USAID) recently concluded that radio has a greater impact on learning than textbooks or teacher education in developing countries. ${ }^{5}$ Radio Anfani hosts

\footnotetext{
${ }^{3}$ See UNDP (2006).

4 The rating for Niger is 0.311 , placing it in last place of 177 countries. See UNDP (2006).

${ }^{5}$ See USAID: A fghanistan, 2004, available at http://www.usaid.gov/locations/asia_near_east/countries/ afghanistan/education.html (last visited Ötober 16, 2007).
} 
"I'd say that you need the radio here. If you want daily news or you want entertainment, it's always radio. Radio is a part of everyone's day-to-day lives. There's always a radio around: in bags, in bed, in the living room. Everyone has one. In the streets, among friends, there's always a radio." -Elderly man in Niamey, Niger's capital city

children from local communities every Wednesday on a special educational program. More than 40 children crowd into the small studio and clamor to answer questions posed by the host. This show has proved very popular with both kids and adults, underscoring the need for more educational programming.

\section{Conclusion}

As seen in the examples above, radio has made tremendous contributions in terms of civic engagement and encouragement of fair, effective, transparent governance; improvement of mutual understanding within and among communities; peer-to-peer learning with in the developing world; and education of people of all ages in Niger.

Radio encourages continuous information exchange that helps reduce social risks and helps people keep a check on power. Politicians tend to favor informed voters and well-covered issues. ${ }^{6}$ This is certainly the case in Niger, where most people use the radio as a tool to monitor the political situation and make decisions largely depending on what they hear on the air waves. For instance, radio helped galvanize the student population in Niamey to speak out against corruption in the education sector. When radio stations publicized the report of the anticorruption committee, which exposed malpractice in the education sector, the youth in Niamey demonstrated for more transparency and better attention to student needs. Activists say such action not only led to the release of 29 student activists, but to higher government attention to the needs of the education system.

Radio's broad appeal comes from its inherent simplicity. Radio programs help show that people face similar problems around the world. In Niger, people look up to other developing countries, such as India and South A frica, and seek to emulate some of their successes on their path to progress. With a rich history in education, health, and development, radio is thus best suited to reaching millions of people in developing nations. Development practitioners would do well to take advantage of this medium to create programs that will keep listeners tuned in and to take proactive steps to improve their condition.

The authors would like to thank Craig Hammer of WBI's Voice and Accountability Program for his contributions to this brief.

\section{References}

Kaufmann, D., A. Kraay, and M. Mastruzzi. 2007. Governance Matters VI: Governance Indicators for 1996-2006. Policy Research Working Paper No. 4280. World Bank, Washington, D.C.

Sposato, Stephen and William. A. Smith. 2005. Radio: A Post Nine-Eleven Strategy for Reaching the World's Poor. Lanham, Md.: University Press of A merica.

Stromberg, David. 2002. "Distributing News and Political Influence," The Right to Tell: The Role of Mass Media in Economic Development. World Bank Institute, World Bank, Washington D.C.

UNDP (United Nations Development Programme). 2006. Human Development Report 2006: Beyond Scarcity: Power, Poverty, and the Global Water Crisis. New York, NY.

WAN (World Association of Newspapers). 2007. World Press Trends 2007. Paris, France.

\footnotetext{
${ }^{6}$ See Stromberg (2002).
}

A bout World Bank Institute (WBI): Unleashing the Power of Knowledge to Enable a World Free of Poverty

The World Bank Institute (WBI) helps countries share and apply global and local knowledge to meet development challenges. WBI's capacity development programs are designed to build skills among groups of individuals involved in performing tasks, and also to strengthen the organizations in which they work, and the sociopolitical environment in which they operate.

WBI Contact:

Mark Nelson; program manager, Capacity Development Resource Center

Tel: 202-458-8041, e-mail: mnelson1@worldbank.org

Ajay Tejasvi; program coordinator, Capacity Development Resource Center

Tel: 202-458-4064, e-mail: anarasimhan@worldbank.org

Visit our website for more information and download the electronic copies of all Capacity Development Briefs at http:// www.worldbank.org/capacity 